\title{
'Two Cultures' in the Study of Religion? - A Response to Håkan Rydving
}

STEVEN J. SUTCLIFFE

University of Edinburgh

I shall concentrate in this response on situating Håkan Rydving's critique of cognitive science of religion (hereafter CSR) within the wider debate on the constitution of disciplinary identity in 'religious studies'. ${ }^{1}$ This issue remains far from resolved, although since 1950 the International Association for the History of Religions and its member organizations have periodically engaged questions of metatheory and disciplinary identity in conference plenaries and publications. The issue is particularly relevant in Anglophone settings, where indeterminacy over what 'religious studies' signifies epistemologically continues to have an impact on departmental resources, on staff and student (self-)selection, and - not least - on the comparative status of the field within the academy. ${ }^{2}$ The careers of brilliant individuals may proceed relatively unburdened by institutional constraints, but it remains the case that the way in which the competent majority corporately represents 'religion' as an object of study requires continuous monitoring of the intellectual warrant for a field of 'religious studies' in the face of powerful

\footnotetext{
${ }^{1}$ While we found many points of agreement in the original plenary session in Stockholm, I have concentrated in this written text on developing my criticisms of Håkan's position to address wider disciplinary issues. I would like to thank Håkan for his forbearance in this regard. I would also like to thank Peter Jackson for inviting me to be a plenary respondent. I acknowledge financial assistance from the British Academy towards attending the conference.

${ }^{2}$ For example, despite the fact that English and Scottish institutions and scholars are well-represented in the history of the field, 'religious studies' in the UK remains curiously fragile, shown by the shrinkage or closure in recent years of some departments or their amalgamation into hybrid departments of 'theology and religious studies' or into wider schools of languages and cultural studies (Sutcliffe 2004; Cox \& Sutcliffe 2006); also by the eagerness of some theologians to assimilate the terminology of 'religious studies' (Ford et al 2005). The internationalization of historiography (Alles 2008) rightly prompts Anglophone analyses to learn from the historical development of sciences religieuses, godsdienstwetenschap, religionswissenschaft, uskontotiede, religionsvetenskap and religionsvitenskap, to mention several important traditions of non-anglophonic scholarship in Europe alone. Nevertheless the hegemonic medium of English and the power and influence of organisations such as the American Academy of Religion suggest that the international fate of 'religious studies' in the foreseeable future is likely to remain closely bound up with Anglophone formations.
} 
exterior forces - cultural, political and economic (Wiegers 2002) - with their own agendas on these matters. Questions of voice and agency, much debated in postcolonial studies and the politics of representation in relation to the subjects of academic research, are also relevant for scholars themselves as producers of knowledge.

This means that the central question raised by Håkan's critique of CSR - whether or not 'religion' is a natural datum or a sociocultural construction-impinges directly on the higher-order, metatheoretical constitution of the field. In this response I shall therefore focus on those points in Håkan's critique with the strongest metatheoretical implications. I will not go into these points in detail; my intention is less to endorse or refute Håkan's position than to place his implicit preferred model for the study of religion in a wider disciplinary context.

His first point, on the 'unsettled epistemological status' of the category 'religion', is clearly related to his final point on the problem of using 'a western folk category' in the analysis of 'mind', also made in the title of his article. The epistemological insecurity of our central category is certainly an important datum. I agree that there seems to be little evidence of cognitivists engaging with significant category critiques by 'culturalist' scholars such as J. Z. Smith and Talal Asad, amongst others. Referential and semantic confusion in different uses (including translations) of the category 'religion' over time and space is a central research question in accounting for the historical and cultural distribution of the phenomena we study. It is significant that the culturalist case is made to rest on the kind of comparative, cross-cultural evidence which Håkan finds to be relatively 'meagre' within the cognitivist data base. Along with this hiatus in empirical testing, Håkan finds a reliance amongst cognitivists on qualitative corroboration of evidence through the accumulation of confirmatory examples, rather than a sustained attempt at falsification. Finally, he identifies a tension between theorists of 'counterintuitivity' such as Boyer and Pyysiäinen, and 'intuitivist' theorists such as Guthrie and Bulbulia, which in turn points to disagreement between non-adaptationist and adaptationist accounts of the evolutionary capacity of religion. ${ }^{3}$

\footnotetext{
${ }^{3}$ In my experience of CSR literature, most of these points are acknowledged at least in part or in passing, although attention to the primary point - the category 'religion' - is scarce. CSR texts do, however, regularly engage with a multidisciplinary literature (inter alia in biology, neuroscience and developmental psychology: see, for example, the 14 pages of sources in Andresen 2001,30-44) that is rare in 'religious studies', and this aspect of CSR sources is insufficiently represented in Håkan's bibliography. In relation to the categorical critique, I suggest that, while a cognitive science of beliefs/representations or a cognitive science of ritual makes sense, strictly speaking a cognitive science of religion (used as a synthetic academic construct) is epistemically ambiguous and could indeed be interpreted as a restatement of sui generis religion, as Håkan suggests, or even as the basis for a new natural theology.
} 
These three points raise substantial metatheoretical questions, not just for CSR but for all IAHR scholars insofar as IAHR includes 'all scholars and affiliates that contribute to the historical, social, and comparative study of religion' ${ }^{4}$ Håkan acknowledges this metalevel of analysis insofar as his points feed a cumulative argument that cognitivists are not practising bona fide natural science but a form of interpretive, qualitative, 'soft' science. ${ }^{5}$ The issue is slightly obscured by the fact that Håkan states rather then demonstrates cognitivists' claims to practise natural science (he provides no references), just as he largely states rather than demonstrates the problems of 'style' and 'hegemonic claims' ${ }^{6}$ which he ascribes to CSR literature. There is a sense, that is, that Håkan is actively constructing metatheoretical 'camps' and 'sides' in the study of religion. He does this quite explicitly in the opening paragraphs: here he identifies 'a clear-cut division between the cognitivists and the rest', which he compares to the difference between 'converted' and 'non-believer'. Later, he extends the differential metaphor to 'insiders' and 'outsiders'. The sum is a picture of the cognitivist as a kind of introverted sectarian, standing apart from what Håkan calls 'the general academic study of religion', or later 'the comparative study of religion'. But what these disciplinary rubrics signify in themselves remains implicit and untheorised, although apparently normative. The metatheoretical dimension of the discussion is thus partly recognised yet partly evaded.

The implicit distinction made here between an 'improper' and a 'proper' form of 'religious studies' must be understood within a wider range of possible disciplinary self-representations which articulate different epistemologies with respect to 'religion'. Clues in his article suggest that Håkan's model is derived from a model of interdisciplinarity based on humanistic and interpretivist traditions. ${ }^{7}$ This particular conception of interdisciplinarity cannot be taken for granted, however, but requires justification and defence. Untheorised interdisciplinarity of this or any kind is conceptually problematic and may also be strategically unhelpful in the cause of comparative disciplinary justification precisely by dint of its unarticulated and undefended premiss. If space permitted, substantive criticism could also

\footnotetext{
4 'What is the IAHR?': www.iahr.dk (accessed 26/2/08)

${ }^{5}$ Arguably CSR has thus far operated more as a theoretical-philosophical psychology than as a full-blown empirical research programme. This may simply represent an early stage of theoretical formulation prior to the cross-cultural empirical testing which Håkan demands (and to which CSR presumably aspires).

${ }^{6}$ Only three references are supplied, all equivocal.

${ }^{7}$ For example, the paper's opening sentence (see below); the approving references in footnote 19 to culturalist deconstructions of 'religion'; the choice of local case studies with a rather limited cross-cultural dimension as examples of research scenarios which challenge the usefulness of CSR; and the mention of possible 'ethical' implications arising from mistaking a local for a universal category, linked to the charge of 'western intellectual imperialism'.
} 
be developed along the lines that liberal interpretivist methodologies on their own are unlikely to be able to account for the full cognitive and social power of 'religion', since 'religion' is not just thought, felt and done reflexively and rationally by its practitioners but also operates at pre-conscious (cognitive, biological) and collective (socialized, ideological) levels. Against Håkan's focus on the 'problem' of CSR, therefore, I want to suggest its potential for re-opening debate on the nature and scope of interdisciplinarity in 'religious studies'.

Håkan's critique ultimately derives from a particular taxonomy of knowledge. His opening sentence makes this plain: 'can religion be explained rather than merely analysed and understood in a fragmentary way?' (my italics). But both his epistemological preference and the taxonomy itself are historically and culturally contingent. The standard modern genealogy traces the difference between 'explanation' and 'understanding' back to the hermeneutical philosophy of Wilhelm Dilthey. As is well-known, Dilthey formulated an epistemological distinction between naturwissenschaften or natural sciences and geisteswissenschaften or human ('mental', 'spiritual') sciences, with their respective goals of erklärung (description in terms of cause and effect) and verstehen (description in terms of intentionality and meaning).

This distinction has since re-emerged at various sites. A useful example is the debate on the 'two cultures' begun by C. P. Snow's 1959 Reith lecture at the University of Cambridge (Snow 1965). ${ }^{8}$ Snow (1905-1980) trained in the natural sciences and conducted early postdoctoral research at the Cavendish laboratory in Cambridge; from 1940 he published a long sequence of novels; and in 1964 he became Parliamentary Secretary in the newly-established Ministry of Technology in Harold Wilson's Labour government in the UK. His biography thus straddled conventional boundaries between science, art and politics. This experience undoubtedly informed his argument in The Two Cultures that the modern academic-intellectual landscape had become divided into two mutually exclusive formations, resulting in a cultural polarization which 'is sheer loss to us all' (Snow 1965, 11). He chose physics and biology as examples of the natural sciences, and literary criticism as the paradigm of the humanities. Between these 'two cultures' he found a state of disinterest and even mutual incomprehension: 'I felt I was among two groups [...] who had almost ceased to communicate' (p. 2) and which

\footnotetext{
${ }^{8}$ Collini (1998, xlii-xliii): 'the scale of the response indicates that this was no merely parochial British concern'. Snow himself mentions discussions in Hungarian, Polish and Japanese (1965, 54).
} 
held 'a curious distorted image of each other' (p. 4). Snow's sympathies lay with the scientific culture, which he felt had been roundly misunderstood. For Snow, the scientists 'have the future in their bones' (p. 11) while the literary intellectuals ${ }^{9}$ were 'natural Luddites' (p. 22) who failed to acknowledge the social and economic benefits of the scientific revolution (p. 24-27). An important thread in Snow's argument is resentment at what he sees as the appropriation of the title of 'intellectual' by literary practitioners to the exclusion of scientists (p. 4). By way of riposte, he asks literary gatherings 'how many of them could describe the Second Law of Thermodynamics', which he famously describes as 'the scientific equivalent of: Have you read a work of Shakespeare's?' (p. 15). Snow describes the responses to this question as 'cold' and 'negative' (p. 15). He deduces from this that 'if I had asked an even simpler question - such as, What do you mean by mass, or acceleration, which is the scientific equivalent of saying, Can you read? - not more than one in ten [...] would have felt that I was speaking the same language' (p. 15). Snow later regretted not choosing molecular biology as his example (p. 73), since this was the branch of science 'likely to affect the way in which men think of themselves more profoundly than any scientific advance since Darwin's' (p. 74). Later the essay becomes preoccupied with the global benefits of applied science, with many of Snow's remarks now sounding naïve and paternalistic. The core issue remains the intellectual impoverishment produced by a 'two cultures' division of academic labour; the solution requires 'rethinking our education' (Snow 1965, 18).

Although Snow's lecture is easily criticized for its anecdotalism and blunt dichotomization, it had considerable impact in the 1960s, precisely the period when 'religious studies' was emerging as an academic formation in the UK and USA. In his introduction to the second edition of Snow's lecture, the intellectual historian Stefan Collini puts the idea of a distinction between two cultures into historical context. He sees it as a product of Romantic 'cultural anxiety' from the late eighteenth/early nineteenth century onward (Collini 1998, ix-x), which in English cultural history was manifested as a series of clashes: 'the Romantic versus the Utilitarian, [Samuel Taylor] Coleridge versus [Jeremy] Bentham, [Matthew] Arnold versus [T. H.] Huxley, and other less celebrated examples' (p.xxxv). Collini argues that previously in western systematic thought 'the interpretation of nature was generally

\footnotetext{
${ }^{9}$ Collini $(1998$, li) waspishly remarks that 'the modern counterparts to Snow's "literary intellectuals" are more likely to meet each other at an academic conference or a campus-based "writers' workshop" '.
} 
regarded as but one element in the all-embracing enterprise of "philosophy"' (p. xxxv), and he points out that the Enlightenment epitome of knowledge, Diderot's L'Encyclopédie, made no distinction of the kind later sought by Dilthey. A particular problem in the Anglophone context is the unusually restricted understanding of 'science', which by 1867 in English had come to mean 'physical and experimental science, to the exclusion of theological and metaphysical'. ${ }^{10}$ Collini notes that the word 'scientist', securely established in William Whewell's The Philosophy of the Inductive Sciences (1840), was first proposed in 1834 by a member of the British Association for the Advancement of Science to describe 'students of the knowledge of the material world' by analogy with 'artist' (Collini 1998, xii). The coinage suggests a contrast between scientific empiricism - studying 'the material world' - and the more imaginative and idealistic work of the arts: in short, naturwissenschaften and geisteswissenschaften.

Snow's own use of the term 'two cultures' is as much strategic trope as historical descriptor. Acknowledging that 'the dialectic is a dangerous process' (p. 9), he nevertheless used the dichotomy to highlight an issue which he feared would otherwise be lost through what he calls 'the technique of the intricate defensive'. By this he meant the tactic employed by opponents to 'ingeniously protect the status quo' by swamping attempts to generalize and systematize data in the details of 'two thousand and two cultures' ( $\mathrm{p}$. 66-67). ${ }^{11}$ In this sense the 'two cultures' trope anticipates more recent tensions in the social sciences between universalists and cultural relativists. The epistemological status of the category 'religion' is the most obvious expression of these tensions within 'religious studies', which reinforces my point that how our central category is theorised bears on the institutional fate of the disciplinary formation. This is not just a matter of defending the territory of 'religious studies' from disciplinary predators - Theology, Social Anthropology, Sociology or Cultural Studies, for example-but more importantly of making a proactive declaration of the positive intellectual difference an academic formation called 'religious studies' can make.

\footnotetext{
${ }^{10}$ Oxford English Dictionary, 'Science', sense 5; cited in Collini (1998, xi-xii). The idea of a 'social' and 'cultural' science would later face a similar pressure.

${ }^{11}$ Ironically Snow, fiercely accused by literary critic F. R. Leavis of being a 'public relations man' for the scientific establishment, had not been 'engaged in first-hand scientific research' for more than 20 years (Collini 1998, xx); 'his preferred ground was [...] the Big Idea: he seized it [...] illustrated it with a few facts and anecdotes taken from widely differing domains, and reiterated it in accessible, forceful prose' (p.xxix). Because Snow also wanted to develop a moral critique of the two cultures' failure to communicate, he was speaking as a 'public intellectual', which raises an additional, topical question in the debate on disciplinary identity in 'religious studies' (cf. Wiebe 2005b). My interest here is restricted to the epistemological dimension.
} 
The metatheoretical resources and commitments for securing this intellectual difference remain a moot point, however. Although sometimes presented as an autonomous discipline, especially by its Victorian pioneers, 'religious studies' or the 'science/study of religions' since the founding of the IAHR and especially since the 1960s has more often been presented as a 'subject field' rather than a 'discipline', particularly in Anglophone contexts (Wiebe 2005a). The result is a mixed, hybrid model of research and teaching in which some methods, theories and topics are privileged and others proscribed. Typically, however, the metatheoretical mechanism for inclusion or exclusion remains mysterious. For example, a fictitious (small) 'religious studies' department consisting in an Indologist, a contemporary Islamicist, a scholar in Buddhist studies and a specialist in new religious movements (NRMs) would be unexceptional (intuitive, to use CSR terminology). A similarly fictitious department consisting in a political scientist, an oral historian, a cognitive scientist and a social geographer would be unusual (counterintuitive). In both cases the operating principles of inclusion and exclusion must be inferred. The first department presents as an apparently casual (but implicitly constrained) selection of synthetic entities ('religions'), which appear in turn to be derived - on the basis of post/colonial contact histories in the case of the Indologist and Islamicist, and in part on the basis of the allure of the exotic and novel in the case of Buddhism and NRMs - from a particular typology: one based arguably on a Victorian 'world religion' prototype (Smith 1998). The second department counter-intuitively constructs 'religious studies' as a field which does not primarily study a typology of substantive entities but functions as a field of empirically-based thematic and methodological expertise, directed by theoretical interests. We can further infer from these two fictitious examples that the most strongly counter-intuitive department of 'religious studies' would consist in a roster of reductive explanatory methodologies based in the natural sciences, eschewing both a typology of 'religions' and the use of interpretive methodologies. If such a department seems 'obviously' off the radar of disciplinary possibilities, this only confirms my point that metatheoretical considerations are operating in and on our field in an implicit, intuitive and therefore uncontrolled fashion.

Like Snow's 'two cultures', the above picture is a crude simplification in order to make a point: that the typical 'interdisciplinary' field model of 'religious studies' is a highly intuitive representation constrained by a series of latent assumptions about inclusion and exclusion based on unarticulated metatheory. An urgent task in re-visiting the question of disciplinary 
identity is to make these metatheoretical assumptions visible and subject to informed debate; this in turn will require us to improve our expertise in areas which are currently poorly represented in 'interdisciplinary religious studies', such as philosophy of science, philosophy of social science, and comparative history and sociology of higher education.

I would agree with Håkan that the culturalist goods of particularity, context and difference remain necessary in any plausible settlement of the scope of methodology in 'religious studies'. But I think the question we now need to ask is, are they sufficient? 'Culture' itself has come to function in some recent 'religious studies' work as a convenient wider matrix of human action and interpretation into which 'religion' can be made to dissolve. In part this move has been made to escape the perils of sui generis religion, in part for perceived theoretical advantages in making common cause with social anthropology and cultural studies. But wholesale lateral movement into 'culture' could be a pyrrhic victory. Like religion, culture does not explain anything in and of itself. Like religion, it is a synthetic category which must be disaggregated. 'What is culture?' is the corollary of the question 'what is religion?'. Interpretive approaches to these questions may be discursively rich, but they are prone to circularity. Used unsystematically, and in isolation from other approaches, they struggle to escape 'the hermeneutic vortex' (Lawson \& McCauley 1993, 217). Both questions invite at minimum a naturalistic supplement to interpretive knowledge, at maximum the rounding out or completion of understanding through identification of cause and effect.

These considerations suggest that dichotomizing 'religious studies' into a struggle between naturwissenschaften and geisteswissenschaften is unhelpful and unnecessary. In the postscript to his original lecture, Snow pondered introducing a 'third culture' into the equation (Snow 1965, 70). He described this 'third culture' as emerging from 'social history, sociology, demography, political science, economics, government [and] psychology' (p. 70). He identified an 'inner consistency' to these disciplines: they were all 'concerned with how human beings are living or have lived ... not in terms of legend, but of fact' (Snow 1965, 70). We could gloss this 'third culture' as historical and socio-anthropological in orientation, characterized by reliance on empirical, intersubjectively testable evidence. The particular characteristic of this 'third culture', according to Snow, is that it 'has, just to do its job, to be on speaking terms with the scientific one' (p. 71).

A 'third culture' has always been present (or at least nascent) within 'religious studies'. In the British case, for example, it is underpinned by a broadly 
'qualitative empirical' methodology (Sutcliffe 2004). The ability of this 'third culture' further to develop what Snow calls 'speaking terms' with (natural) science could be stimulated by carefully selected and appropriately devised research programmes between naturalists and culturalists. These would of course need to work out tensions between interpretive and explanatory agendas, as well as tensions between different levels of explanation per se: that is, between the micro-level/cognitive and the macro-level/socio-cultural, since CSR seems prone to reducing the latter to the former. But it is surely not a question of generating either meaning or causality, either the ideographic or the nomothetic: a fully interdisciplinary 'field' model should be competent in comparing and assessing the knowledge claims of both approaches. The higher-order problem of deciding the relationship between interpretation of meanings and explanation of causes constitutes the reflexive metatheoretical commentary on the practice of 'religious studies' that the field must engage in to be a fully constituted interdisciplinary enterprise.

In other words, Håkan's representation of the reaction by 'religious studies' to the 'problem' of CSR is a variation on the unresolved question of disciplinary identity. Understood in this way, engagement between culturalists and naturalists could serve to generate disciplinary renewal, encouraging the production of a more widely cast model of interdisciplinarity rather than fostering suspicion and disengagement. I therefore appreciate Håkan's critique of CSR for the disciplinary questions it raises. But I leave the final word to C. P. Snow $(1965,16)$ : 'The clashing point of two subjects, two disciplines, two cultures [...] ought to produce creative chances. In the history of mental activity that has been where some of the break-throughs came.'

\section{Bibliography}

Alles, Gregory D. (ed.)

2008 Religious Studies: A Global View. London: Routledge.

\section{Andresen, Jensine}

2001 Introduction: towards a cognitive science of religion. - Jensine Andresen (ed), Religion in Mind: Cognitive Perspectives on Religious Belief, Ritual and Experience, 1-44. Cambridge: Cambridge University Press. 


\section{Collini, Stefan}

1998 Introduction. - C. P. Snow, The Two Cultures [2nd edition], vii-lxxi. Cambridge: Canto/Cambridge University Press.

\section{Cox, James L. \& Steven J. Sutcliffe}

2006 Religious Studies in Scotland: a persistent tension with Divinity. - Religion 20, 1-28.

Ford, David F. \& Ben Quash \& Janet Martin Soskice (eds)

2005 Fields of Faith: Theology and Religious Studies for the Twenty-First Century. Cambridge: Cambridge University Press.

\section{Lawson, E. Thomas \& Robert N. McCauley}

1993 Crisis of Conscience, Riddle of Identity: Making Space for a Cognitive Approach to Religious Phenomena. - Journal of the American Academy of Religion 61(2), 201-23.

\section{Snow, C. P.}

1965 The Two Cultures and a Second Look: an expanded version of the Two Cultures and the Scientific Revolution. Cambridge: Cambridge University Press. (The Two Cultures first published 1959; The Two Cultures: A Second Look first published 1963; first issued together 1964.)

\section{Smith, Jonathan Z.}

1998 Religion, Religions, Religious. - Mark C. Taylor (ed.), Critical Terms for Religious Studies, 269-284. Chicago: Chicago University Press.

\section{Sutcliffe, Steven J.}

2004 Introduction. Qualitative Empirical Methodologies: An Inductive Argument. - Steven J. Sutcliffe (ed.), Religion: Empirical Studies. A Collection to Mark the 50th Anniversary of the British Association for the Study of Religions, xvii-xliii. Aldershot: Ashgate.

\section{Wiebe, Donald}

2005a Religious Studies. - John R. Hinnells (ed.), The Routledge Companion to the Study of Religion, 98-124. London: Routledge.

2005b The Politics of Wishful Thinking? Disentangling the Role of the Scholar-Scientist from that of the Public Intellectual in the Modern Academic Study of Religion. - Temenos 41(1), 7-38.

\section{Wiegers, Gerard (ed.)}

2002 Modern Societies and the Science of Religions. Leiden: Brill. 